\title{
Follow-up regarding inappropriate and cloned clinical histories on radiology request forms for sick children
}

\author{
S. Bruce Greenberg • Leann Linam • \\ Chetan Chandulal Shah
}

Received: 10 July 2013 / Accepted: 11 July 2013 /Published online: 10 August 2013

(C) Springer-Verlag Berlin Heidelberg 2013

Sir,

This letter is to follow up with additional information related to our article titled "Inappropriate and cloned clinical histories on radiology request forms for sick children" [1]. The discussion section of the article describes our plans to improve the clinical histories submitted with radiographic requests. Since submission of the paper, we have implemented the changes.

Routine daily films have been eliminated from the neonatal intensive care unit. A 3.5-min video titled "Improving clinical ordering of radiographs" was prepared for all NICU staff involved in the ordering process and is available through streaming. The web link is: http:// imediasrv.archildrens.org/mediasite $5 /$ Viewer/?peid=d0e1b 1322ab740069af7059f29ef81421d. Laminated cards listing common mistakes and suggestions for appropriate clinical history were distributed to NICU staff.

One month following the intervention, the NICU portion of the original study was repeated. Eleven of 63 studies (17\%) were inappropriate, which was a better than $50 \%$ improvement from the original study. A chi-square test showed that the improvement was significant (chi square $=5.69, P=0.017$ ). In the original study $22 \%$ of clinical histories were cloned. Cloning was entirely absent in the repeat study.

In summary, simple interventions resulted in a reduction of inappropriate histories by greater than $50 \%$ and in the elimination of cloning.

Conflicts of interest None

\section{Reference}

1. Shah CC, Linam L, Greenberg SB (2013) Inappropriate and cloned clinical histories on radiology request forms for sick children. Pediatr Radiol. doi:10.1007/s00247-013-2648-7 [Epub ahead of print]
S. B. Greenberg $(\bowtie) \cdot$ L. Linam • C. C. Shah

Department of Radiology, University of Arkansas for Medical

Sciences, Arkansas Children's Hospital, 1 Children's Way,

Slot \#105, Little Rock, AR 72202, USA

e-mail: greenbergsbruce@uams.edu 